\title{
Quantification of the Influence of Factors Causing Time and Cost Overruns in Tanzanian Construction Projects
}

\author{
Daniela Daniel Ndunguru ${ }^{1 *}$, Ferdinand Niyonyungu' ${ }^{2}$, Xiangfei Yang1 \\ ${ }^{1}$ School of Traffic and Transport, Lanzhou Jiaotong University, Lanzhou, China \\ ${ }^{2}$ School of Civil Engineering, Lanzhou Jiaotong University, Lanzhou, China \\ Email: *danielandunguru@yahoo.com
}

How to cite this paper: Ndunguru, D. D., Niyonyungu, F., \& Yang, X. F. (2020). Quantification of the Influence of Factors Causing Time and Cost Overruns in Tanzanian Construction Projects. Open Journal of Business and Management, 8, 2133-2147. https://doi.org/10.4236/ojbm.2020.85130

Received: July 27, 2020

Accepted: September 1, 2020

Published: September 4, 2020

Copyright $\odot 2020$ by author(s) and Scientific Research Publishing Inc. This work is licensed under the Creative Commons Attribution International License (CC BY 4.0).

http://creativecommons.org/licenses/by/4.0/

\begin{abstract}
Tanzania suffers problems of cost and time overruns in the construction business. Many factors are contributing to the cost and time overruns in Tanzania construction projects. There are many publications in different countries about cost and time overruns in construction projects, these publications show that the problem of overruns varies from country to country. This variation gives the idea that even in Tanzania there is a need for researches concerning cost and time overruns. Some researchers worked on the problems of cost and time issues in Tanzania but narrowing only on the identification of factors. This study used the survey to identify the frequent factors in Tanzania and the quantitative assessment of the completed projects to quantify the influence of each factor contributing to cost and time overruns. To come up with the results shows the extent influence of each factor in overruns in expected in this research and it will be the key pillar in construction management to fight against overruns.
\end{abstract}

\section{Keywords}

Time Overruns, Cost Overruns, Construction Industry, Tanzania

\section{Introduction}

The success of the construction projects is characterized by multiple factors but three of them are the basic and most important, these are time, cost, and quality. These factors must be maintained in a proper balance to achieve the satisfaction of different participants of construction projects; that is ending the project on time, within the budget, and at the required quality. 
Project management tools and techniques play an important role in the effective management of a project. Therefore, management lies in the management tools and techniques used to manage the project. Project management involves managing the resource-workers, materials, machines, money, and methods used (Giridhar \& Ramesh, 1998). Some of the projects are managed effectively and efficiently resulting in satisfactory results while others face many problems which led to cost and time overruns.

Construction project comprises two main phases: the preconstruction phase which is the period between the initial conception of the project and award of the contract and which is the period from the award of the contract when the construction is going on (Giridhar \& Ramesh, 1998). In all phases, there is an occurrence of time and cost overruns but major and many causes of cost and time overruns occur during the construction phase (Frimpong, Oluwoye, \& Crawford, 2003).

However, the challenges of delay and cost overruns remain frequent in Tanzania and around the world in general.

Many researchers in Tanzania and worldwide made efforts on the problems of cost and time overrun by assessing different factors and different types of construction projects. In the research of Kaming and his colleagues (Kaming, Olomolaiye, \& Harris, 2010) about the factors of cost and time overruns in Indonesian tall buildings, it was revealed that inadequate planning, poor labor productivity, and design changes were the major factors affecting time. For cost overruns, it was found that they are impacted by the level of complexity of projects, increases of material costs, inaccurate estimation of bills of quantities. In South Africa, the assessment performed on the time and cost overruns of world cup stadiums projects in South Africa in 2010 (Baloyi \& Bekker, 2011), on 18 factors ten found to be high ranked with the contribution of $85 \%$ of the cost overruns where an increase in material costs, inaccurate material estimates and shortage of skilled labor took the first places.

Some researchers found a powerful correlation between project delays and $t$ escalation, therefore, they concluded that the same factors are contributing to both time and cost overruns (Sambasivan \& Soon, 2007) (Aibinu \& Jagboro, 2002). Other researchers took construction delays and cost overruns factors as one (Apolot, Alinaitwe, \& Tindiwensi, 2013) (Le-Hoai, Lee, \& Lee, 2008) (Morris, 1990).

Geraldine (Kikwasi, 2013) found that design changes, delays in payment to contractors, and information delays are the highest-ranked causes of delays and disruptions in Tanzanian construction projects. Moreover, research by Rwakarehe and Mfinanga conducted on 7 major road construction projects has indicated that inadequate design contributes $85 \%$ and $41 \%$ to time and cost overruns respectively in Tanzanian road construction projects (Rwakarehe \& Mfinanga, 2014).

Azziz and his colleague used a literature survey and questionnaire to establish 
a list of cost overruns causes in different countries and different circumstances and he finally designed a questionnaire of 293 causes of time overruns (Aziz \& Abdel-Hakam, 2016). The research conducted by Norman et al. revealed that 662 projects, with a budget of 40 billion riyals have experienced severe delays, which is a very huge number. With $12.2 \%$ of cases being related to regulatory and administrative obstacles and $82 \%$ being relayed to material and technical capability contractors (Noman, 2018).

There is two main reason why this research on the influence of factors causing time and cost overruns was conducted, first, the factors affecting the performance of construction projects differs from country to country, the project to project and this depends on project circumstances (Sullivan \& Harris, 1986). Second, although most of the factors causing projects "cost and time overruns" are known, still the problem of overruns persists. This can probably be because different construction participants do not have sufficient information on the magnitude of the influence of the factors causing projects' cost and time overruns. Quantification of the influence of the factors for project cost and time overruns can be among the important information to help solve the problem.

The main objective of this research is to quantify the influence of factors causing time and cost overruns in Tanzania construction projects. It also addresses the following specific objectives: Identify factors causing construction cost and time overruns, establish the extent of influence of each factor on time and cost overruns and propose the measures to curb the problem of overruns.

The study provides information to the consultants, contractors, owners, and others that are involved in the construction industry on the real situation of cost and time overruns problem. It will give them the proper image of the contribution of each factor of cost and time overruns by quantifying its influence.

Also, the study proposes some technical recommendations that will help in the project performance as far as cost and time are concerned.

\section{Background of the Construction Industry in Tanzania}

Although the construction industry in Tanzania keeps on growing, it faces many challenges that include, inadequate local capacity, mobilizing adequate resources in terms of finance, equipment, and human resources, achieving international competitiveness, increasing the share in work opportunities for local contractors and consultants, improving industry performance in the poor economic environment and so forth (Works, 2003). From the discussion of key actors in Tanzanian construction projects, the following diagram in Figure 1 was designed to illustrate how overruns are managed.

\section{Performance of Tanzanian Construction Projects in Terms of Time and Cost}

The research of Rwakarehe and his colleague revealed that as far as the overruns are concerned in road constructions many projects had overruns like the 


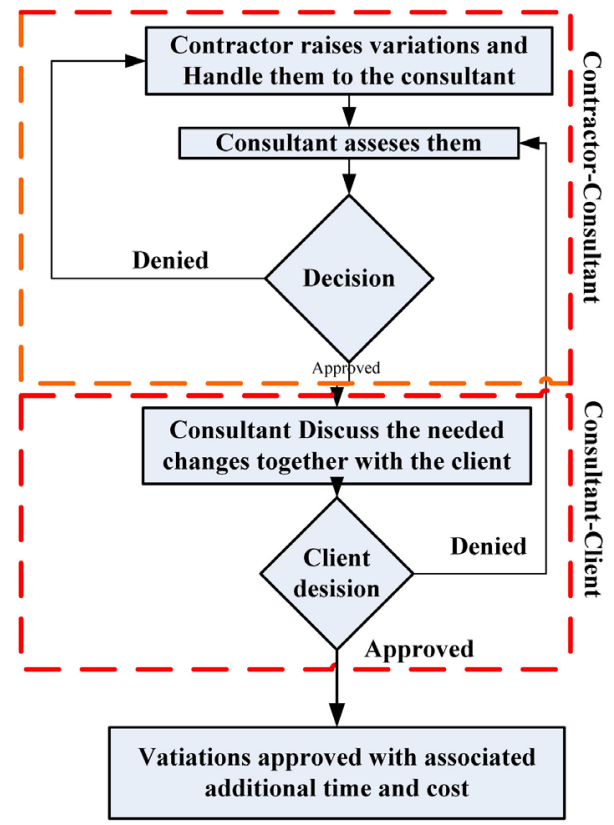

Figure 1. The framework of delays and cost escalation management.

Mwanza/Shinyanga-Tinde road project completed in 2007 with an overrun of 15.7 months that represents $65 \%$ of the total estimated duration and the total cost overrun rate of $85 \%$, Nzega-Isaka road project completed in 2007 with 8.5 months that represents $36 \%$ of estimated duration and the total cost overrun rate of $97 \%$ and so forth (Rwakarehe \& Mfinanga, 2014). Although there are many good methods of time and cost estimation it is not sufficient only to determine the cost and time of construction projects but also to manage and supervise day to day the flow of execution is a very important aspect. Here we can mention that there many ways that the time and cost can be wasted only by lack of seriousness in supervision. Generally, the performance of construction projects is measured basing on the three factors which are the scope or quality of the product, the time of completion, and the cost. Challenges that face construction projects are those that cause the bad performance of those three factors. The construction industry in Tanzania is facing many challenges related to the lack of sufficient funds, shortage of professionals which leads to poor management of projects, and corruption related to high internal competition which leads to poor bidding and tendering. All these have a big effect on time, cost, and quality performance of construction projects.

\section{Definition of Terms}

A better understanding of the terms time and cost overruns is crucial to their assessments.

\subsection{Cost Overruns}

Cost overruns refer to as budget increase, cost increase, or cost growth. It can 
also be clearly defined as the difference between actual project cost and estimated project cost. But Cost overrun may also be defined differently by different researchers depending on the intended purpose of their researches. For example, Nijkamp and Ubbels and Odeck define cost overruns as the difference between forecasted and actual construction costs (UBBELS, 1999) (Odeck, 2004). That means that the budget at the decision to build stage is used as a reference to determine the cost overrun of the project. The actual construction cost is the accounted construction cost at the time of project completion.

In many types of research that are performed in past years by different people, they came up with different results referring to what they wanted to asses as far as the cost overruns are concerned, but also the definition of the cost overruns as the key pillar of the problem was differently interpreted as shown above. For instance, the findings of the overruns were different because the reference points were set differently.

Cost overrun may be determined using any definition above but it is very important to fix the reference point used in determining it and mention it in the results. Also, it is very important to differentiate between cost overruns that occur before the award of the contract to those and are incurred during the construction stage up to the completion.

In this paper cost overrun is defined as the difference between the actual project cost at the practical completion and the estimated project cost at the award of the contract.

Figure 2 shows the differences between cost overruns between two reference points.

\subsection{Time Overruns}

Time overrun is defined as the difference between actual and estimated project duration. Accumulations of delays in completion of individual works result in overall time overrun of the project. Delay refers to something happening at a later time than planned, expected, and specified in a contract or beyond the date that the parties agreed upon for the delivery of the project. A delay is also defined as slowing down of work without stopping entirely. Always the time overrun was to be calculated by taking reference to the statement period of the works

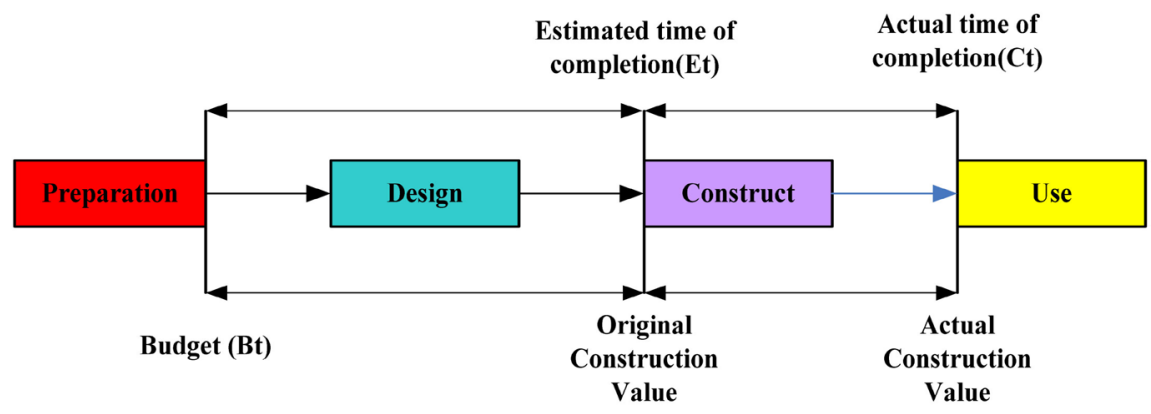

Figure 2. Determination of overruns. 
and comparing the estimated period of completion and the actual period of completion. The causes of delays have different factors that influence them and referring to these factors is where the exact definition, determination of influence, and key measures can be achieved.

\subsection{Causes of Time and Cost Overruns}

Projects are supposed to be carried out in the estimated duration of time and within the budget. But that rarely happens because other unforeseen things may arise during project execution and have the impacts on project completion and/or project cost. Many researchers around the world investigated the cause of time and cost overruns. In Nigeria, the most frequent causes of delays and were found to be improper planning, lack of proper communication, and shortage of supply (Kasimu, 2012). In Malaysia, the research has been found that cost overruns and time overruns are major issues with respondence of $89 \%$ and $92 \%$ of agreement respondent rate (Rahman, Memon, Nagapan, Latif, \& Azis, 2013). In Egypt, the top ten delay causes according to their frequencies were found to be the type of project bidding and award (negotiation, lowest bidder), ineffective planning and scheduling of the project, variation of orders/change of scope by project owner during construction, late in receiving and approving design documents by the owner, finance, and payments of completed work by owner, poor site management and supervision, the low productivity level of labors, difficulties in financing the project by contractors, effects of subsurface conditions (like soil, high water table, etc), and slow decision making (Marzouk \& El-Rasas, 2014). In Ghana, the results of a questionnaire survey on groundwater construction projects showed 26 factors responsible for project delays and cost overruns where monthly payment difficulties, poor contract management, material procurement, inflation, and contractor financial difficulties took the first five places respectively (Frimpong, Oluwoye, \& Crawford, 2003). In India, material market rate, contract modification, high level of quality requirement, project location, rework of bad quality performance, changing subcontractor's company, unclear specification, lack of technical skills, and lack of experience in similar projects were found to be among the first causes of time overruns while the escalation of material price, frequent breakdown of the construction plant and equipment, rework, shortage of materials and fluctuation in money exchange were found to be the principal causes of cost overruns with a high rank (Subramani, 2014) (Shanmugapriya, 2013).

There are many causes of cost and time overruns, the causes are slightly common in all countries but their magnitude differs from country to country referring to the conditions of each country. The unequal contribution of the factors on the overruns studied by Lucius and Michel during research on overruns of construction of stadiums for the world cup (Baloyi \& Bekker, 2011), where they come up with findings that there is an interrelationship between factors causing overruns which can cause some factors to have a high magnitude on 
influence on cost and time overruns. For instance, some factors that are considered as standalone factors may be the results of the cause of the other factors, taking the example of wrong material take-off which can be the result of the design changes, poor skills levels which could have results on poor supervision, and other silent factors like language and cultural differences (Baloyi \& Bekker, 2011).

The precise quantity of influence of each factor is needed so that the factors that have a big influence are known and big attention is made on avoiding or settling them, the others that are contributing less will not be left out but they will not get much attention as the others will get because some of them will be already included in those important factors. It means that for example if the wrong material takes off is the result of design changes, to put much attention on the design change problems can resolve or reduce the wrong material take-off problem at a certain level.

\section{Research Methodology}

To achieve the objectives of the study, questionnaires are designed from a review of current literature, reports, and interview from experienced key actors in Tanzanian construction projects. Questionnaires are then distributed from consultants, contractors, and owners that participated in the selected 200 construction projects completed between 2015 and 2020. The methodology used in this project is represented in Figure 3.

The respondents were asked to rank the causes of time and cost overruns in terms of frequency of occurrence and influence on overruns (severity) using a five-point scale of 0 to 4 . Which will also be used as a quantification tool as shown in Table 1.

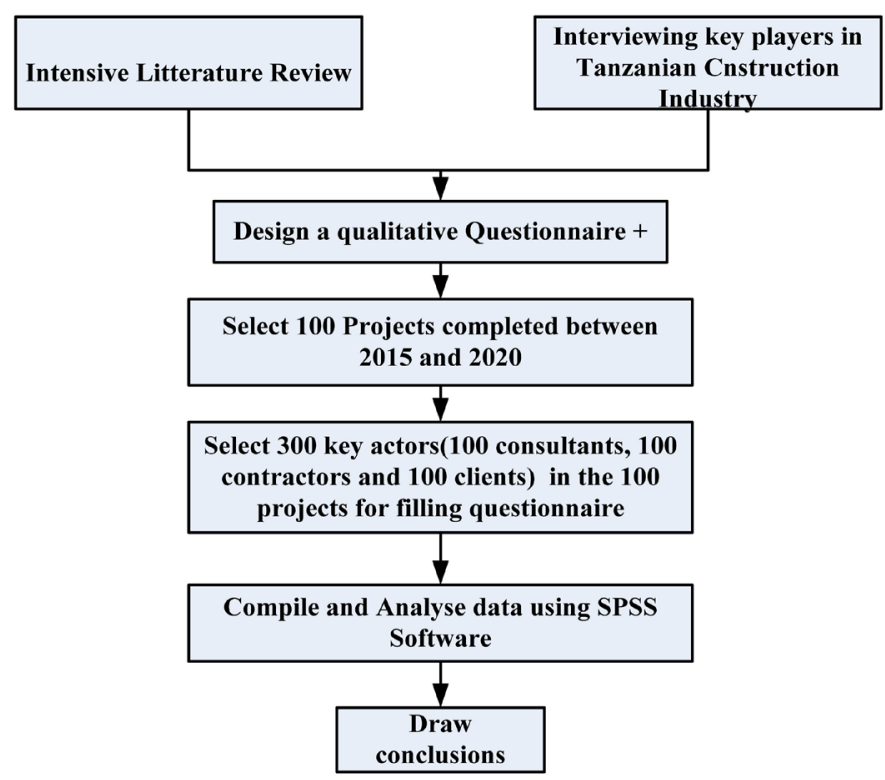

Figure 3. Designed Research methodology. 
Table 1. Respondents rankings and their meaning.

\begin{tabular}{ccc}
\hline Numerical value & $\begin{array}{c}\text { Meaning for the } \\
\text { frequency of occurrence }\end{array}$ & $\begin{array}{c}\text { Meaning for severity } \\
\text { (influence) }\end{array}$ \\
\hline 0 & Never happen & No \\
1 & Rarely & Minor \\
2 & Sometimes & Moderate \\
3 & Often & High \\
4 & Always & Extremely high \\
\hline
\end{tabular}

Frequency index as the measure of the occurrence of the factor,

$$
\text { F.I. }=\frac{\sum_{0}^{4} a_{i} n_{i}}{A N}
$$

where, F.I. is the frequency index, a represent the weight assigned to each response, $n=$ frequency of each response, $A$ the highest weight given to factors (which is 4 in our case) and $N$ the total number of all responses.

Also, the severity index which expresses the severity of the factor which cost and time overrun is calculated as,

$$
\text { S.I. }=\frac{\sum_{0}^{4} a_{i} n_{i}}{A N}
$$

where, S.I. is the severity index, represents the weight assigned to each response, $n$ the frequency of each response, $A$ the highest weight given to the factors (which is 4 in our case), and $N$ the total number of responses.

The importance index which expresses the overview of the combination of the two indices is the product of the two, IMP.I $=$ F.I. ${ }^{*}$ S.I.

Reliability is referred to as the degree of consistency with which an instrument measures the attribute it is designed to measure. As far as the data collection is concerned, the test-retest reliability tool was used in this research to minimize the error due to bias in designing a questionnaire and in collecting them. Two same questionnaires were distributed to one respondent but in different time and methods, hard copies of questionnaires were distributed to respondents, and later an e-questionnaire was also sent through the respondent's email then after answers are compared. Among all respondents, 98.1\% gave the same answers to both questionnaires. Also, more open-ended questions are provided to let the respondents give us what will be not provided on the closed-ended questions. The questionnaires will be left to the respondents so that they take time to read and attentively answer questions that will be asked with full of comfort.

Also, during the analysis of the report, big attention will be paid so that the errors during assessing the reports are avoided. Also, the Authors did their best to work closely with the administration of the estate department for the clarifications and explanations where needed. 
The validity of an instrument is the degree to which an instrument measures what is intended to measure. That is the extent to which the instrument results permit the researcher to draw warranted conclusions about the characteristics of the individuals studied.

The questionnaires are designed from the information gained from the review of literature, and all questionnaires are designed in simple language so that are very clear and specifically related to the research objectives. The validity was checked first by my supervisor and by comparing the results from the questionnaire and that of the project reports analysis. My supervisor has more than twenty years of research experience in this field and by his expert judgment, he confirmed the questionnaires to be valid.

The number of respondents that will submit an incomplete questionnaire will be reported so that the thread to the validity can be judged. To maintain the confidentiality rule, no identifying information was entered onto the questionnaires, and questionnaires will be only numbered after data was collected.

\section{Analysis of Results}

42 water projects, 137 building projects, and 121 road construction projects were examined. Among them, 39 water projects, 101 buildings, and 121 road construction projects are public and the remaining are owned by private companies and/or individuals as shown in Table 2(a).

Among 300 interviewees, 44 contractors companies, 32 consultants, and 1 client were foreign as shown in Table 2(b). As per Table 3, 101 of the interviewees have more than 20 years, 147 have between 10 to 20 years and the remainder have less than 10 but more than 5 years of working experience in Tanzanian construction projects.

Table 2. (a) Projects demographic; (b) Respondent demographic in terms of their role.

(a)

\begin{tabular}{ccc}
\hline & \multicolumn{2}{c}{ Projects } \\
\cline { 2 - 3 } & Public owned & Private owned \\
\hline Water projects & 39 & 36 \\
Building projects & 101 & 0 \\
Road construction projects & 121 & 36 \\
\hline
\end{tabular}

(b)

\begin{tabular}{ccc}
\hline & \multicolumn{3}{c}{ Respondents } \\
\cline { 2 - 3 } & Local & Foreign \\
\hline Contractors & 44 & 56 \\
Consultants & 32 & 68 \\
Owners & 1 & 99 \\
\hline
\end{tabular}


Table 3. Experience of respondents.

\begin{tabular}{cc}
\hline Experience (in Years) & Number of Respondents \\
\hline 5 to 10 & 101 \\
10 to 20 & 147 \\
More than 20 & 52 \\
\hline
\end{tabular}

\subsection{Factors of Time Overruns}

The results from interviews with key actors in the construction industry in Tanzania, 19 major causes causing time overruns as shown in Table 4, and 19 majors causes of cost overruns as shown in Table 5 were investigated. Among causes of time overruns, The results from the questionnaire show that unexpected inflation/material escalation, adverse effect of weather, lack of proper communication and coordination between parties, inadequate production of raw material, late in certification and payment of completed work, technical incompetence and poor organization structure and additional works/changes by the client are the most predominant causes as shown in Figure 4(a). Additional works/change orders by client, late in certification and payment of completed work, inadequate production of raw material, and lack of proper communication and coordination between parties are the top four factors with high frequency with frequency index of $0.8883,0.8508,0.8725$, and 0.86 respectively as shown in Figure 4(b). All these causes can be grouped into one group related to improper project management. Frequent design changes, cash flow, and financial difficulties faced by contractors, inadequate labor/skill availability, and technical incompetence, and poor organization structure are found to be among the causes that severely affect time overruns of construction projects with $0.805,085417$, 0.7475 , and 0.78333 respectively (see Figure 4 (c). These causes also accept inadequate/skill availability are all in the same group of improper project management related causes. By combining both frequency and severity of causes of time overruns, lack of proper communication and coordination between parties, frequent design changes, inadequate production of raw material, cash flow and financial difficulties faced by contractors, late in certification and payment of completed work, technical incompetence and poor organization structure and additional works/change orders by the client are found to be the most important. From these results, it can be concluded that improper project management plays an important part in construction delays and cost escalations.

\subsection{Factors of Cost Overrun}

Among the factors of cost overruns, inaccurate estimates, fluctuation in prices of materials, wastage on-site, and frequent design changes are the most frequent causes of cost overruns in constructions with a frequency index of 0.89833 , $0.81333,0.91$, and 0.8866 respectively Figure 5(a). Except for fluctuation in the price of material, other factors fall into the group of improper project management. 
Table 4. Factors of time overruns.

\begin{tabular}{cc}
\hline No & Factors \\
\hline 1 & Unexpected inflation/material price escalation \\
2 & Inaccurate estimates \\
3 & Improper planning and scheduling \\
4 & Fluctuation in prices of material \\
6 & The adverse effect of weather \\
7 & Poor contract documentation and management \\
8 & Lack of experience in related project \\
9 & Inadequate site investigation/unexpected ground condition \\
10 & Frequent design changes \\
11 & poor project/site management and supervision \\
12 & inadequate production of raw material \\
13 & cash flow and financial difficulties faced by contractors \\
14 & inadequate labor/skill availability \\
15 & change in the scope of the project \\
16 & lechnical incompetence and poor organization structure \\
17 & additional works/change orders by client \\
18 & contractor's poor procurement process \\
19 &
\end{tabular}

Table 5. Factors of cost overruns.

\begin{tabular}{cc}
\hline No & Factors \\
\hline 1 & unexpected inflation/material price escalation \\
3 & inaccurate estimates \\
4 & Frequent breakdown of construction equipment \\
5 & fluctuation in prices of material \\
6 & Rework caused by unexpected weather conditions \\
7 & lack of experience in related project \\
8 & Fluctuation in the money exchange rate \\
9 & Additional work at the owner's request \\
10 & The high maintenance cost of machinery \\
11 & Shortage of materials \\
12 & Lack of information flow between parties \\
13 & High quality of work required \\
14 & The high cost of machinery \\
15 & Mistake during construction \\
16 & Foor project/site management \\
17 & Frequent design changes \\
18 & \\
19 & \\
\hline & Whadequate site investigations/Unexpected ground conditions \\
\hline
\end{tabular}




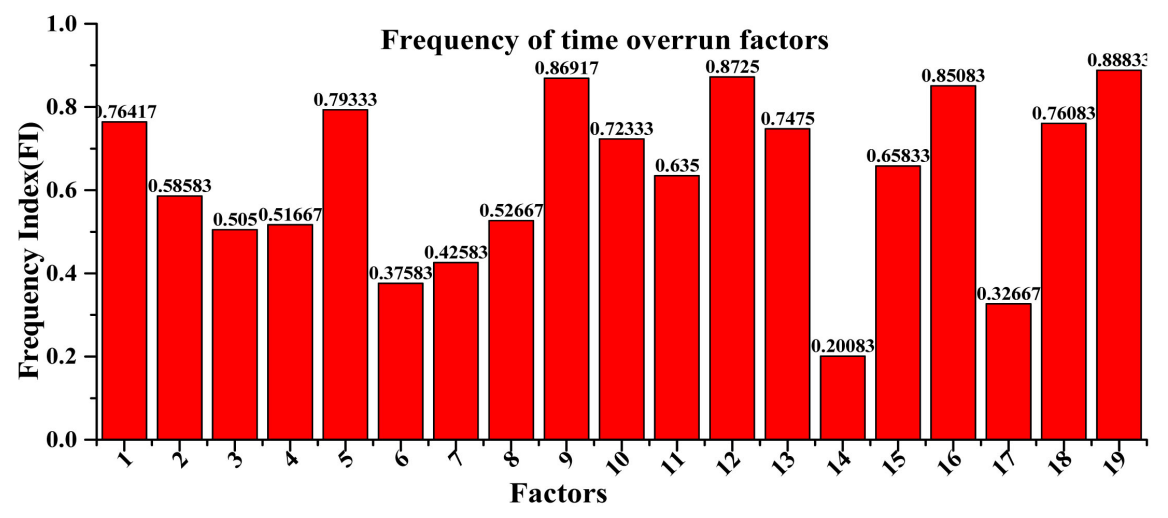

(a)

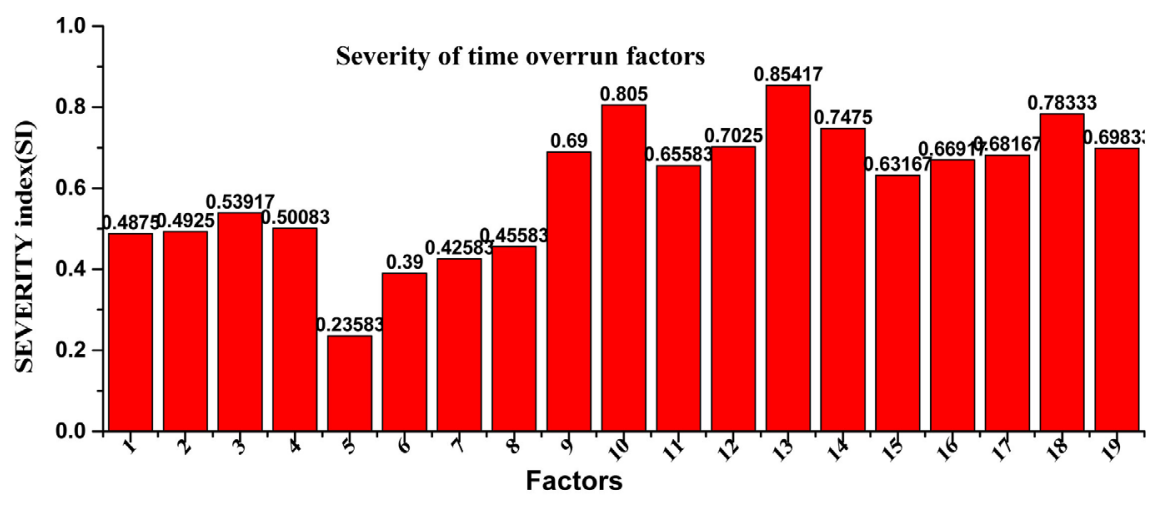

(b)

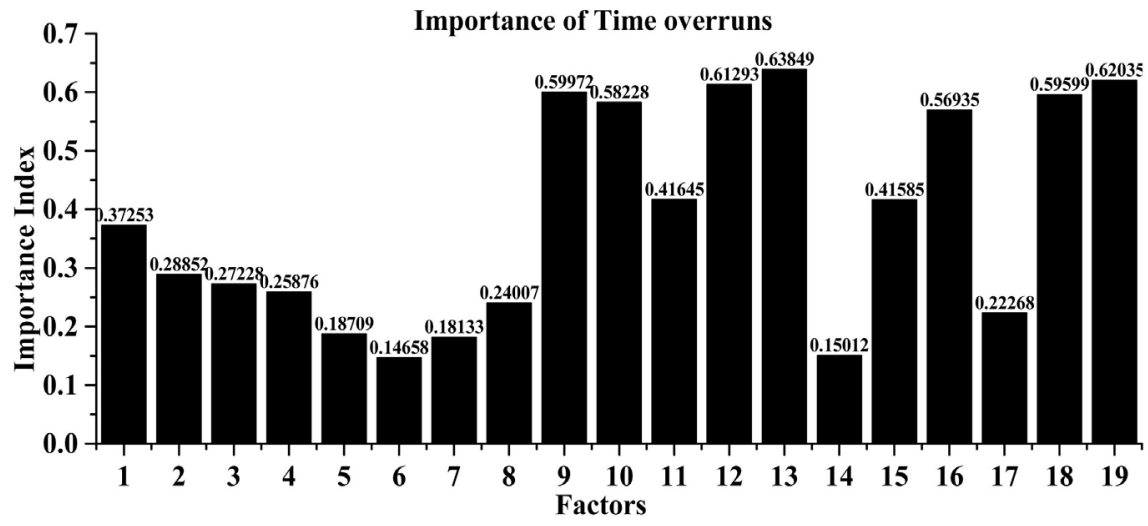

(c)

Figure 4. Factors of time overruns indices.

The high maintenance cost of machinery, high quality of work required, and frequent design changes are the top factors that severely affect the cost overruns of Tanzanian construction projects with a severity index of $0.811167,0.82683$, and 0.88268 respectively as shown in Figure $5(\mathrm{~b})$. When the effects of cost and time overruns are combined, it has been found that frequent design changes are the most important causes of cost overruns as represented in Figure 5(c). Frequent design changes can also be classified as improper project management related causes. 


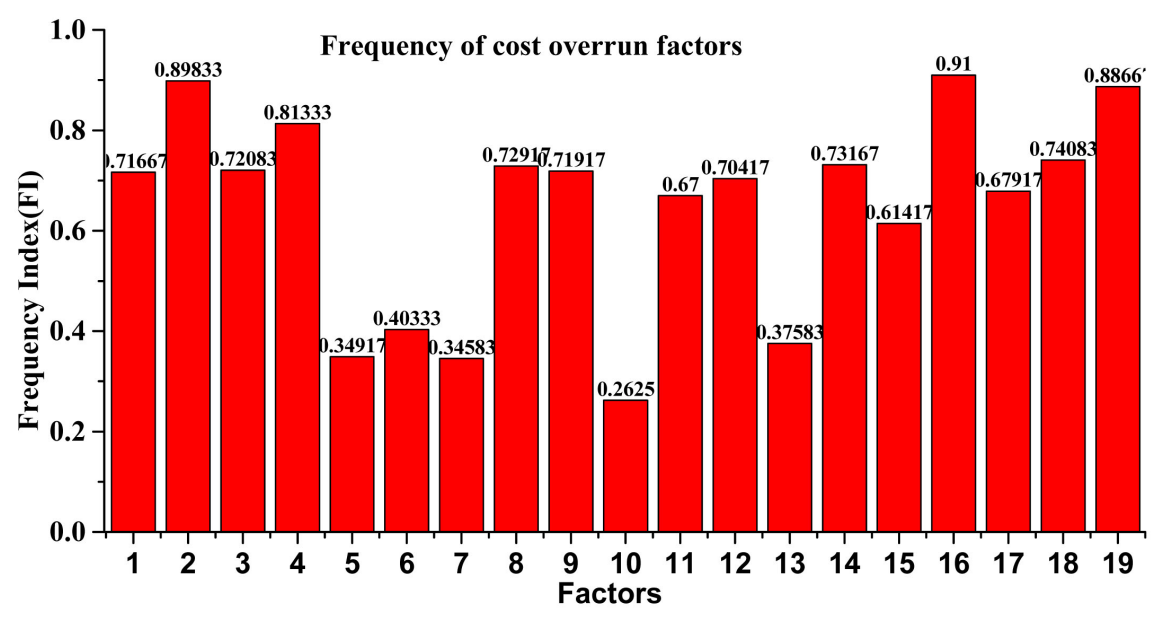

(a)

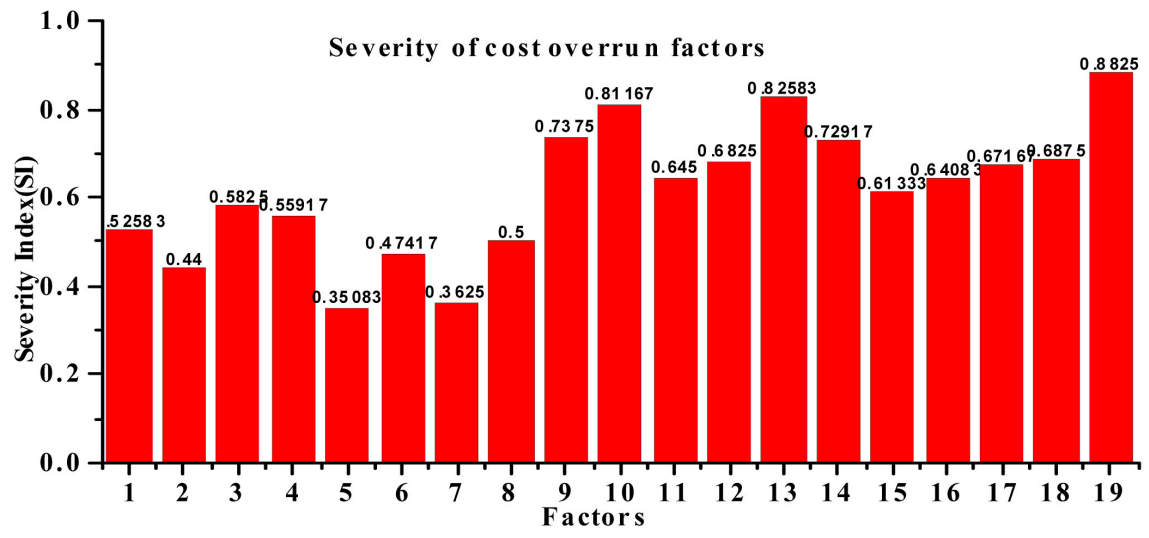

(b)

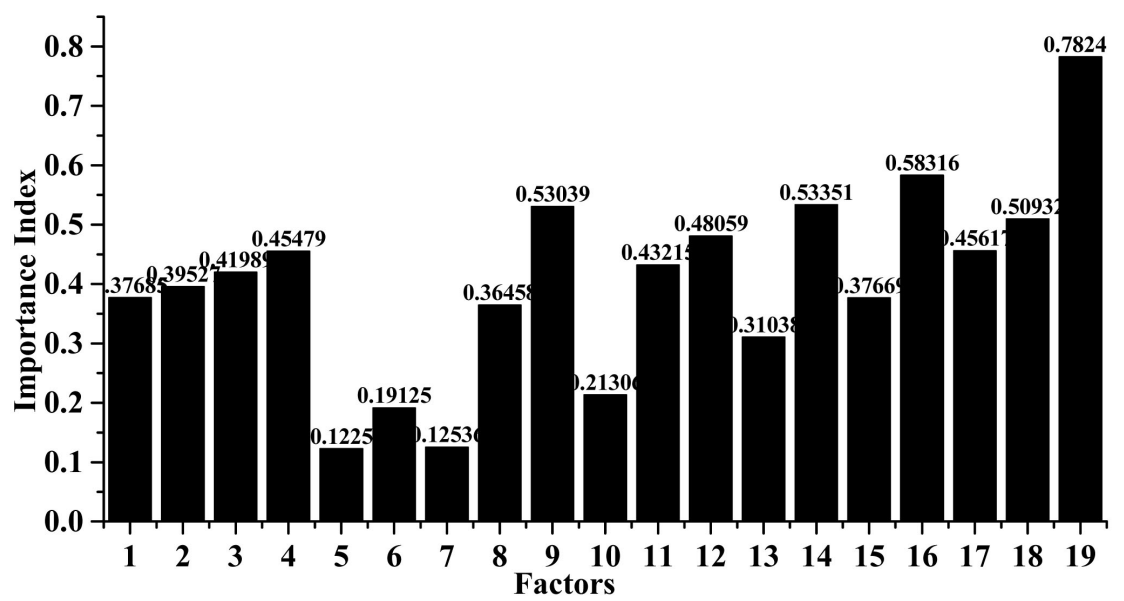

(c)

Figure 5. Factors of cost overruns indices.

\section{Conclusion}

The analysis of results revealed that most of the causes of time and cost overruns are related to improper construction project management. Their results showed a high agreement between respondents on the frequency and severity of causes 
of construction project delays and cost escalations. It can also be noted that there is an interrelationship among the factors, for example, unexpected inflation/material price escalation, fluctuation in prices of material, Fluctuation in the money exchange rate, and high maintenance cost of machinery can be related to inaccurate estimates. Although this research has taken only 190 projects, the results could be representative of the Tanzanian construction projects in general or the research can be further extended for other countries.

Authors recommend that much attention must be paid when selecting project managers of projects. Not only, Experience and qualification of project managers must be seriously taken into consideration, but also there must be law enforcement to know who must bear the responsibility of the overruns. The coordination between all key players in construction projects must be extremely respected and given attention to the successful management of the project.

A more quantitative analysis of project reports, by analyzing completion certificates, payments certificates, demand, and approval of changes and other information included in completed project files is recommended for future research. Also, a study on the interrelationship between different factors is recommended. For example, fluctuation in prices of materials may have an indirect or direct relationship with an inaccurate estimation of the project cost.

\section{Conflicts of Interest}

The authors declare no conflicts of interest regarding the publication of this paper.

\section{References}

Aibinu, A., \& Jagboro, G. (2002). The Effects of Construction Delays on Project Delivery in Nigerian Construction Industry. International Journal of Project Management, 20, 593-599. https://doi.org/10.1016/S0263-7863(02)00028-5

Apolot, R., Alinaitwe, H., \& Tindiwensi, D. (2013). Investigation of the Causes of Delay and Cost Overrun in Construction Projects in Uganda's Public Sector. Journal of Construction in Developing Countries, 18, 33-47.

Aziz, R. F., \& Abdel-Hakam, A. A. (2016). Exploring Delay Causes of Road Construction Projects in Egypt. Alexandria Engineering Journal, 55, 1515-1539. https://doi.org/10.1016/j.aej.2016.03.006

Baloyi, L., \& Bekker, M. (2011). Causes of Construction Cost and Time Overruns: The 2010 FIFA World Cup Stadia in South Africa. Acta Structilia, 18, 51-67.

Frimpong, Y., Oluwoye, J., \& Crawford, L. (2003). Causes of Delay and Cost Overruns in Construction of Groundwater Projects in a Developing Countries; Ghana as a Case Study. International Journal of Project Management, 21, 321-326. https://doi.org/10.1016/S0263-7863(02)00055-8

Giridhar, P., \& Ramesh, K. (1998). Effective Management of Turnkey Projects. AACE International Transactions, PM.04.1-PM.04.5.

Kaming, P. F., Olomolaiye, P. O., \& Harris, G. D. (2010). Factors Influencing Construction Time and Cost Overruns on High-Rise Projects in Indonesia. Construction Man- 
agement and Economics, 15, 83-94. https://doi.org/10.1080/014461997373132

Kasimu, M. A. (2012). Significant Factors That Causes Cost Overruns in Building Construction Project in Nigeria. Interdisciplinary Journal of Contemporary Research in Business, 3, 775-780.

Kikwasi, G. (2013). Causes and Effects of Delays and Disruptions in Construction Projects in Tanzania. Australian Journal of Construction Economics and Buildings, 1, 52-59. https://doi.org/10.5130/ajceb-cs.v1i2.3166

Le-Hoai, L., Lee, Y. D., \& Lee, J. Y. (2008). Delay and Cost Overruns in Vietnam Large Construction Projects: A Comparison with Other Selected Countries. KSCE Journal of Civil Engineering, 12, 367-377. https://doi.org/10.1007/s12205-008-0367-7 https://link.springer.com/article/10.1007/s12205-008-0367-7

Marzouk, M. M., \& El-Rasas, T. I. (2014). Analyzing Delay Causes in Egyptian Construction Projects. Journal of Advanced Research, 5, 49-55. https://doi.org/10.1016/j.jare.2012.11.005

Morris, S. (1990). Cost and Time Overruns in Public Sector Projects. Economic and Political Weekly, 25, 154-168.

Noman, A. B. (2018). Causes of Delays in Public and Private Construction Projects in Saudi Arabia. Journal of Construction Management, 54, 71-78.

Odeck, J. (2004). Cost Overruns in Road Construction-What Are Their Sizes and Determinants? Transport Policy, 11, 43-53. https://doi.org/10.1016/S0967-070X(03)00017-9

Rahman, I. A., Memon, A. H., Nagapan, S., Latif, Q. B., \& Azis, A. A. (2013). Time and Cost Performance of Construction Projects in Southern and Central Regions of Peninsula Malaysia. In 2012 IEEE Colloquium on Humanities, Science and Engineering (pp. 52-57). Kota Kinabalu: IEEE. https://doi.org/10.1109/CHUSER.2012.6504280

Rwakarehe, E. E., \& Mfinanga, D. A. (2014). Effect of Inadequate Design on Cost and Time Overrun of Road Construction Projects in Tanzania. Journal of Construction Engineering and Project Management, 4, 15-28. https://doi.org/10.6106/JCEPM.2014.4.1.015

Sambasivan, M., \& Soon, Y. W. (2007). Causes and Effects of Delays in Malaysian Construction Industry. International Journal of Project Management, 25, 517-526. https://doi.org/10.1016/j.ijproman.2006.11.007

Shanmugapriya, S. (2013). Investigation of Significant Factors Influencing Time and Cost Overruns in Indian Construction Projects. International Journal of Emerging Technology and Advanced Engineering, 3, 734-740.

Subramani, T. S. (2014). Causes of Cost Overrun in Construction. IOSR Journal of Engineering, 4, 1-7.

Ubbels, P. N. (1999). How Reliable Are Estimates of Infrastructure Costs? A Comparative Analysis. International Journal of Transport Economics, 26, 23-53.

Works, T. M. (2003). Construction Industry Policy-Dar es Salaam Ministry of Work 2003 Tanzania: Ministry of Works. Dar es salaam: Tanzania Ministry of Works. 